\title{
Phytoprotection
}

\section{Résumés des conférences du symposium}

\section{La phytoprotection, 100 ans de découvertes : un tremplin vers} l'avenir!

Volume 89, numéro 2-3, décembre 2008

Journée commémorative du centenaire de la société de protection des plantes du Québec

Centennial Commemoration of the Québec Society for the Protection of Plants

URI : https://id.erudit.org/iderudit/038252ar

DOI : https://doi.org/10.7202/038252ar

Aller au sommaire du numéro

Éditeur(s)

Société de protection des plantes du Québec (SPPQ)

ISSN

0031-9511 (imprimé)

1710-1603 (numérique)

Découvrir la revue

Citer ce document

(2008). Résumés des conférences du symposium : la phytoprotection, 100 ans de découvertes : un tremplin vers l'avenir! Phytoprotection, 89(2-3), 175-177. https://doi.org/10.7202/038252ar d'utilisation que vous pouvez consulter en ligne.

https://apropos.erudit.org/fr/usagers/politique-dutilisation/ 
Société de protection des plantes du Québec / Société d'entomologie du Québec $100^{\circ}$ Assemblée annuelle / $135^{\circ}$ Assemblée annuelle

\author{
Québec Society for the Protection of Plants / Québec Entomological \\ Society \\ 100th Annual Meeting / 135th Annual Meeting
}

Québec (Québec), 20 et 21 novembre 2008

Québec (Québec), 20 and 21 November 2008

\title{
Résumés des conférences du symposium La phytoprotection, 100 ans de découvertes: un tremplin vers l'avenir!
}

\author{
PHYTOPROTECTION 89: 175-177
}

La petite histoire de la pathologie végétale : que nous a-t-elle enseigné?

R.R. Bélanger. Département de phytologieFSAA, Centre de recherche en horticulture, Université Laval, Québec (Québec), Canada G1V OA6

La Société de protection des plantes du Québec (SPPQ) célèbre cette année son $100^{\circ}$ anniversaire de fondation, fait marquant puisqu'il confère à la SPPQ le titre de la plus vieille société dédiée à la protection des plantes en Amérique du Nord, devançant la Société américaine de phytopathologie (APS) de quelques semaines. Depuis les superstitions des Romains à l'égard des dieux de la rouille aux tribulations de Prévost avec l'Académie française, en passant par la famine irlandaise, la dispute opposant Smith et Fischer et I'explosion du génie génétique à la suite de la découverte d'un plasmide de transfert chez Agrobacterium tumefaciens, I'histoire de la phytopathologie est jalonnée de faits inusités, de tragédies et de controverses, mais aussi de personnalités marquantes et de découvertes qui ont changé à tout jamais notre façon de vivre. Ce centenaire de la SPPO offre une belle opportunité d'apprécier les progrès remarquables accomplis par les phytopathologistes depuis la fondation de la Société dans un environnement souvent hostile et sceptique. Seules la détermination et la passion de nos prédécesseurs auront assuré à la science de la phytopathologie la reconnaissance et la notoriété qu'elle connaît aujourd'hui. Si les 100 premières années auront été celles de validations et de découvertes pionnières, que nous réservent les 100 prochaines? Les nouveaux outils de biologie moléculaire offrent des opportunités qui étaient inconcevables il y a à peine 10 ans. On peut ainsi anticiper l'ingénierie de nouveaux cultivars possédant toutes les caractéristiques spécifiques de résistance voulues à l'égard de différents agents pathogènes. Toutefois, la globalisation des marchés, les inquiétudes à l'égard de l'environnement et des plants transgéniques, ou encore le marché pressenti des biocarburants viendront dicter en grande partie les orientations de la recherche. Les phytopathologistes d'aujourd'hui et de demain, à l'instar de leurs collègues pionniers, font et continueront de faire face à plusieurs défis sociaux et économiques qui influenceront leurs approches scientifiques. Les changements climatiques auront également pour effet de modifier la carte de distribution des agents pathogènes et de nouveaux ennemis deviendront les défis de demain. La leçon à tirer des 100 premières années est assurément que tout est en évolution constante. L'apparition de résistance des ravageurs des cultures aux pesticides est un exemple éloquent que la science doit s'adapter aussi rapidement que le font les agents pathogènes. On peut espérer que, forts de ce savoir, les futurs phytopathologistes auront appris de I'histoire et des exploits et erreurs des confrères qui les ont précédés pour assurer la sécurité de la production alimentaire et végétale pour encore bien des années.

La lutte aux mauvaises herbes: une bataille sans fin!

D. Bernier. Direction de l'innovation scientifique et technologique, Ministère de l'Agriculture, des Pêcheries et de I'Alimentation du Québec, Québec (Québec), Canada G1R 4X6

La lutte aux mauvaises herbes ne date pas d'hier; la Bible en fait même mention à plusieurs reprises. $C^{\prime}$ est toutefois au cours du $X X^{\mathrm{e}}$ siècle que les découvertes et innovations se seront succédées et entrecroisées à un rythme effréné. En 1946, I'arrivée des premiers herbicides de synthèse sur le marché apportait une solution qui paraissait être extraordinaire. En 1947, un spécialiste du MAPAQ signait un article intitulé: "Ce merveilleux 2,4-D! ". De nos jours, la littérature sur le 2,4-D est devenue gigantesque. Les articles sur ce produit sont si nombreux, tant pour vanter ses mérites que ses désavantages, qu'il est difficile de s'y retrouver même pour les experts... et la saga n'est 
toujours pas terminée! Selon les cultures, nous avons à choisir parmi une longue liste de produits tout aussi performants les uns que les autres. Nous devons bien sûr tenir compte des mauvaises herbes présentes, mais aussi du type de pratique culturale, des risques pour la santé humaine et pour l'environnement, de la résistance, de la dérive, des OGM, des cultures subséquentes, etc. Dans un contexte favorisant la lutte intégrée, I'utilisation de moyens mécaniques, le développement de l'agriculture biologique, les attentes du consommateur, et quoi encore... facile le désherbage? Pas du tout! La lutte aux mauvaises herbes est une science et les mauvaises herbes sont de redoutables ennemis en constante évolution.

\section{L'entomologie agricole au Québec: une évolu- tion distincte?}

J. Brodeur', M. Roy et J. Doyon'. 'Institut de recherche en biologie végétale, Université de Montréal, Montréal (Québec), Canada H1X 2B2; ${ }^{2}$ Direction de l'innovation scientifique et technologique, Ministère de I'Agriculture, des Pêcheries et de l'Alimentation du Québec, Québec (Québec), Canada G1P 3W8

Au cours de cette conférence, nous identifierons quelques-unes des étapes historiques de I'entomologie agricole au Québec. Nous débuterons avec les travaux de certains naturalistes, pionniers de l'entomologie au Québec, puis nous poursuivrons en décrivant les étapes charnières de l'évolution des approches en phytoprotection et conclurons avec un compte-rendu de la situation actuelle. L'ensemble sera mis en parallèle avec ce qui a été observé ailleurs dans le monde. Non exhaustive et pas nécessairement chronologique, notre démarche se veut avant tout une appréciation personnelle du cheminement de l'entomologie agricole québécoise, selon son propre contexte et sur la base de ses succès et lenteurs.

\section{L'évolution de la résistance chez les ravageurs ciblés par les cultures $\mathrm{Bt}$ \\ Y. Carrière. Department of Entomology,} University of Arizona, Tucson, Arizona, USA

Les cultures transgéniques qui produisent des toxines de la bactérie du sol Bacillus thuringiensis (Bt) sont largement utilisées à travers le monde. Ces cultures sont très efficaces pour la lutte contre certains ravageurs du maïs et du coton et représentent un outil avantageux pour la lutte intégrée. Puisque l'évolution de la résistance au Bt chez les ravageurs ciblés risque d'éliminer ces bénéfices, la stratégie refuge est utilisée pour ralentir l'évolution de la résistance. Le succès de cette stratégie requiert que la résistance soit récessive et que les refuges produisent suffisamment d'individus sensibles qui se croisent aux rares individus résistants pour réduire I'héritabilité de la résistance. La stratégie refuge est plus efficace lorsque des coûts sont associés à la résistance (le fitness des individus résistants est inférieur au fitness des individus sensibles en l'absence de toxine $\mathrm{Bt}$ ) et la résistance est incomplète (le fitness des individus résistants est diminué sur les cultures Bt compara- tivement aux cultures non-Bt). L'expression des coûts associés à la résistance est fréquemment affectée par les conditions environnementales. L'utilisation de refuges qui augmentent ces coûts pourrait donc représenter un moyen efficace pour ralentir ou prévenir l'évolution de la résistance. De même, la production de plantes transgéniques qui augmentent la résistance incomplète pourrait augmenter l'efficacité de la stratégie refuge. Après 12 ans d'utilisation intensive des cultures $\mathrm{Bt}$, la résistance au maïs et au coton $\mathrm{Bt}$ s'est développée chez trois ravageurs. Cependant, les données suggèrent que la stratégie refuge a contribué à prolonger la durabilité des cultures Bt.

\section{De Pasteur au PCR : évolution du diagnostic des maladies des plantes}

R. Hamelin. Ressources naturelles Canada, Service canadien des forêts, Centre de foresterie des Laurentides, Québec (Québec), Canada G1V 4 C7

Le diagnostic des maladies des plantes et des arbres est une étape fondamentale de toute forme de gestion des ravageurs: on doit connaître l'agent causal avant de penser à le réprimer. Un bon diagnostic requiert l'identification de l'agent pathogène à partir des symptômes causés et, si possible, par l'isolement de l'organisme. Les problèmes inhérents à cette approche sont la difficulté d'isoler les organismes qui croissent lentement ou qui sont biotrophes et la difficulté à différencier morphologiquement les espèces proches. Les méthodes utilisées pour isoler les organismes étaient jusqu'à récemment les mêmes que celles développées à la suite des travaux de Pasteur à la fin du XIX ${ }^{e}$ siècle. Au début des années 1990, une nouvelle méthode basée sur l'amplification de l'ADN a provoqué une révolution dans le domaine du diagnostic et du monitoring moléculaire. Cette méthode permet de détecter un ADN cible directement à partir de tissus infectés ou de matériel prélevé sur le terrain, comme du sol, et d'amplifier et de détecter les microorganismes sans avoir à en faire de culture. Des méthodes de diagnostic moléculaire ont été développées contre certains des agents pathogènes les plus importants pour la foresterie québécoise, dont le chancre scléroderrien, les agents de pourriture racinaire, les rouilles et le Phytophthora ramorum. Parmi les derniers développements, on a maintenant la capacité de faire du diagnostic quantitatif par PCR en temps réel et de multiplexier, c'est-à-dire d'utiliser simultanément plusieurs sondes d'ADN. Par exemple, on peut faire un test avec des sondes qui ciblent divers niveaux hiérarchiques (famille, genre ou espèce) ou encore inclure une sonde qui cible la plante hôte ou l'insecte vecteur. Nous avons développé de telles approches pour le $P$. ramorum en combinant dans un seul test quatre sondes ciblant la plante hôte (gène RUBISCO universel), le groupe Oomycète (région ribosomique ITS), le genre Phytophthora (gène beta-tubuline) et l'agent pathogène $P$. ramorum (région ribosomique ITS). Ce niveau de redondance augmente de façon considérable la fiabilité des tests. En présence de l'agent pathogène, on s'attend à ce que toutes les sondes donnent un signal. En présence d'un nouveau Phytophthora, les trois premières 
sondes vont donner un signal, mais pas la dernière. Enfin, si la sonde ciblant la plante ne donne pas de signal, on doit conclure que la réaction a échoué et que le test doit être recommencé. Donc, cette approche nous permet de réduire à la fois les taux de faux négatifs et de faux positifs. Le niveau d'information générée $n$ 'indique que la pointe de l'iceberg. On s'attend, dans les années à venir, à voir un niveau $d$ 'information encore plus élevé et d'avoir des tests PCR qui indiqueront aussi le degré de virulence et I'origine géographique de l'agent pathogène détecté.

Biotechnologie, changements climatiques, biocarburants, crise alimentaire: la malherbologie au cœur des préoccupations du $\mathrm{XXI}^{\mathbf{e}}$ siècle

A. Légère. Agriculture et Agroalimentaire Canada, Saskatoon (Saskatchewan), Canada S7N OX2

Les plantes que l'on désigne comme "nuisibles" ou "mauvaises" sont une création de l'entreprise humaine et comme cette dernière, les espèces recevant cet attribut varient selon les époques. À preuve, certaines espèces anciennement honnies se trouvent maintenant au rang de candidates pour la production de biocarburants ou de plate-forme pour produits pharmaceutiques. Ces espèces adventices, retrouvant ainsi leurs lettres de noblesse, ne perdent pas leurs propriétés de "mauvaises herbes" pour autant. II faut donc développer des systèmes de production en prenant en compte leurs particularités. II faut également repenser certains systèmes de production pour les cultures plus traditionnelles. Les plantes adventices qui réussissent à contrer les pratiques de désherbage (levées tardives, biotypes résistants aux herbicides, etc.) font concurrence aux cultures, dérobant ainsi rendements et profits. La présence de populations spontanées issues de cultures transgéniques dans les cultures subséquentes constitue un problème de désherbage pour le producteur. Aussi, selon les régions, on trouve des adventices apparentées aux cultures transgéniques, lesquelles facilitent les flux géniques et la persistance des transgènes dans l'environnement. D'autre part, si les changements climatiques permettent de réviser les zones d'adaptabilité des cultures, il en va de même pour les espèces adventices. II faut déjà composer avec des aires de distribution plus étendues et de nouvelles espèces nuisibles. II faut donc de toute urgence repenser les stratégies de désherbage, et ce, dans les milieux agricoles, forestiers, aquatiques et urbains. Les conséquences de la présence de plantes nuisibles dans tous ces milieux sont économiques, sociales et environnementales, et souvent immédiates. De toute évidence, la malherbologie constitue une discipline de première importance pour la résolution de problèmes qui mobilisent les médias quotidiennement. Cependant, les solutions ne pourront venir qu'au prix d'un réengagement vis-à-vis de la malherbologie, tant du secteur privé que public.

\section{Évolution dans le temps de la flore des mau- vaises herbes au Québec \\ $R$. Néron. Direction de I'innovation scientifique et technologique, Ministère de l'Agriculture, des}

\author{
Pêcheries et de l'Alimentation du Québec, \\ Québec (Québec), Canada G1P 3W8
}

La flore des mauvaises herbes présente dans les cultures s'explique bien sûr par le climat et la géographie. Cependant, sa composition a évolué dans le temps au même rythme que l'agriculture. La liste des mauvaises herbes ainsi que les outils pour les réprimer ont beaucoup changé au cours des ans. Cette présentation dresse, à l'aide de documents d'archives et d'études sur le terrain, un portrait grossier de cette évolution. Plus de 1000 ans avant notre ère, les autochtones du Saint-Laurent pratiquaient la culture sur brûlis. Ils cultivaient en association du maïs, des haricots et des courges. Les courges étaient utilisées pour la lutte aux mauvaises herbes. Dès le $\mathrm{XVI}^{\mathrm{e}}$ siècle, au début de la colonisation, de nombreuses espèces d'origine européenne ont été introduites avec les cultures potagères et vivrières. Par la suite, après la conquête du Québec par les Anglais, I'agriculture s'est développée à une plus large échelle. L'arrivée de colons de la Nouvelle-Angleterre et l'intégration de nouvelles techniques de culture amenèrent toute une gamme de nouvelles espèces. Avec l'ère moderne, l'agriculture du Québec connaît une augmentation de la superficie cultivée. La mécanisation et surtout l'accès à de nouveaux moyens de protection entraînent un changement dans les cultures et, par conséquent, dans la flore des mauvaises herbes. De nos jours, les techniques de conservation du sol, l'apparition de biotypes résistants aux herbicides et l'arrivée d'espèces exotiques envahissantes continuent d'agir sur cette flore.

\section{Cent ans de recherche sur la tordeuse, et ce n'est pas fini!}

J. Régnière. Ressources naturelles Canada, Service canadien des forêts, Centre de foresterie des Laurentides, Québec (Québec), Canada G1V 4C7

La tordeuse des bourgeons de l'épinette a été, et demeure, I'un des plus importants filons de la recherche en écologie des populations. Depuis plus de 100 ans, notre compréhension du comportement démographique de cet insecte forestier ne cesse d'évoluer. Elle est passée des grands principes généraux, et parfois même téléologiques, à une description plus mécaniste et empirique. Les chercheurs de plusieurs générations successives ont exploré de plus en plus profondément les processus écologiques reliés aux épidémies, ainsi que les principaux facteurs impliqués dans leur modulation spatio-temporelle. II est intéressant de revoir comment ont évolué les concepts de base entourant cette problématique et leurs implications en termes de protection et d'aménagement. II est aussi intéressant de considérer les développements récents en dynamique des populations de l'insecte, ainsi que le comportement inusité de la nouvelle épidémie naissante, dans un contexte de changements climatiques. Enfin, étant donné ce progrès, on est en droit de se demander ce que sont les grandes questions qui restent à poser en ce qui a trait à la tordeuse des bourgeons de l'épinette, en particulier, et à l'étude de l'écologie des populations, en général. 